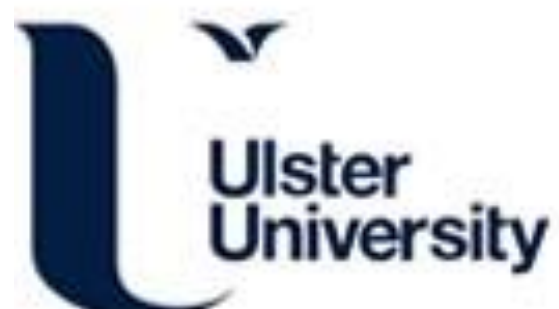

\section{Connectivity and vagility determine beta diversity and nestedness in North American and European freshwater fish}

Griffiths, D. (2017). Connectivity and vagility determine beta diversity and nestedness in North American and European freshwater fish. Journal of Biogeography, 44, 1723-1733. https://doi.org/10.1111/jbi.12964

Link to publication record in Ulster University Research Portal

\section{Published in:}

Journal of Biogeography

Publication Status:

Published (in print/issue): 01/08/2017

DOI:

10.1111/jbi.12964

\section{Document Version}

Publisher's PDF, also known as Version of record

\section{General rights}

Copyright for the publications made accessible via Ulster University's Research Portal is retained by the author(s) and / or other copyright owners and it is a condition of accessing these publications that users recognise and abide by the legal requirements associated with these rights.

\section{Take down policy}

The Research Portal is Ulster University's institutional repository that provides access to Ulster's research outputs. Every effort has been made to ensure that content in the Research Portal does not infringe any person's rights, or applicable UK laws. If you discover content in the Research Portal that you believe breaches copyright or violates any law, please contact pure-support@ulster.ac.uk. 


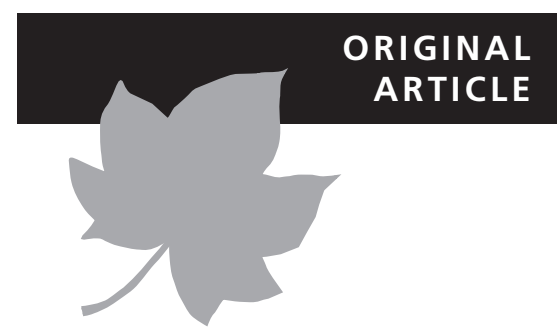

\title{
Connectivity and vagility determine beta diversity and nestedness in North American and European freshwater fish
}

\author{
David Griffiths ${ }^{*}$
}

School of Environmental Sciences, University of Ulster, Coleraine BT52 1SA, UK

${ }^{*}$ Correspondence: David Griffiths, School of Environmental Sciences, University of Ulster, Coleraine BT52 1SA, UK.

E-mail: d.griffiths@ulster.ac.uk

\section{ABSTRACT}

Aim This study assesses the extent to which biogeographic patterns in freshwater fish beta diversity and nestedness are due to dispersal limitation, from differences in dispersal opportunity across geographic areas and in dispersal ability across species.

Location Europe and the Atlantic and Pacific realms of North America (NA), east and west of the Continental Divide.

Methods The effects of glaciation, realm shape, connectivity, current climate and vagility on regional-level beta diversity and nestedness were investigated. Turnover and nestedness-resultant dissimilarity components of beta diversity and the nestedness metric based on overlap and decreasing fill (NODF) were calculated from regional species lists and the contributions of turnover and segregation to nestedness structure quantified.

Results Geographic distance was a stronger predictor of beta diversity than climatic and environmental heterogeneity distances. Species range shapes varied with postglacial colonization direction, being more extensive in an east-west direction in Europe than in Atlantic NA. Turnover increased with declining connectivity, in unglaciated areas, and in non-migratory species. Species were significantly less nested than expected because of high turnover and withinrealm heterogeneity in regional faunas. Deviations from nestedness were greater in unglaciated areas and in migratory species. Non-migrants, but not migrants, exhibited coincident range boundaries.

Main conclusions Spatial trends in beta diversity and nestedness in freshwater fish in NA and Europe result primarily from differences in postglacial recolonization opportunity across realms and in dispersal ability across species. Multiple metrics are necessary to identify the processes determining the spatial structure of species assemblages.

\section{Keywords}

anti-nestedness, beta diversity, dispersal limitation, freshwater fish, glaciation, idiosyncrasy, latitudinal gradients, nestedness-resultant dissimilarity, species segregation, turnover

\section{INTRODUCTION}

Regional variation in species composition can result from dispersal limitation, that is failure to reach suitable sites and, in better dispersers, from spatial variation in species niche requirements and habitat suitability as a consequence of climatic or productivity differences (Baselga et al., 2012a; Keil et al., 2012). This study tests the hypothesis that spatial trends in beta diversity and nestedness largely stem from recolonization differences following Pleistocene glaciations (Leprieur et al., 2011; Baselga et al., 2012a,b; Dobrovolski et al., 2012; Wen et al., 2016), a legacy of past rather than current environmental conditions. Recolonization depends on dispersal opportunity (physical connectivity between regions and/or suitable habitat) and on dispersal ability (from differences in species vagility and/or physiology). 
To address this hypothesis the factors determining beta diversity and nestedness need to be identified. Spatial variation in species composition can be decomposed into two components: replacement (turnover) occurs when species replace each other spatially, usually from niche/habitat differences or dispersal barriers (Whittaker \& Fernández-Palacios, 2007), whereas nestedness-resultant dissimilarity reflects species richness differences resulting from nestedness (Baselga, 2010). Nestedness itself occurs when species present at one site are a subset of those found at more species-rich sites from, for example, differential dispersal or extinction (Ulrich et al., 2009). Conversely, anti-nestedness, where assemblages show fewer co-occurrences of species across sites than expected by chance (segregation), encompasses patterns resulting from high turnover and/or mutually exclusive distributions, within species ranges which do (checkerboard distributions) or do not (non-inclusive sets) overlap spatially (Almeida-Neto et al., 2007). Amongst others, regional differences in habitat and species pools have been suggested as generating anti-nestedness (Matthews et al., 2015). Despite nestedness-resultant dissimilarity not differentiating between these different nestedness structures, few studies have calculated both direct and indirect (nestedness-resultant) measures (Tisseuil et al., 2012; Aranda et al., 2013; Dapporto et al., 2014; Si et al., 2015), distinguished between nestedness and anti-nestedness or identified why anti-nestedness occurred (Matthews et al., 2015): this study does all three.

Freshwater fish are ideal for investigating how environmental factors and species traits determine variation in species composition. Some are spatially constrained, varying in their ability to recolonize habitats following glacial disturbance because of differences in vagility and because some species are confined to freshwater, whereas others spend some of their life in, or can tolerate, salt water and thereby access other catchments. Beta diversity is correlated with spatial, climatic and regional heterogeneity factors in freshwater fish in North America (NA) and Europe (Leprieur et al., 2009; Baselga \& Leprieur, 2015): no factor dominated in NA but reduced connectivity from mountain barriers was particularly important in Europe. Leprieur et al. (2011) showed that global patterns in turnover of salt-water intolerant freshwater fish correlated with post-Quaternary climatic change: turnover tended to dominate in unglaciated areas, whereas nestedness-resultant dissimilarity was more important in formerly glaciated areas, consistent with differential colonization/extinction. The only large-scale (Ontario, NA) direct analysis of nestedness showed that turnover dominated in southern lake fish assemblages while nestedness was more important to the north (Henriques-Silva et al., 2013). Dias et al. (2014) demonstrated that historically connected river basins had more fish species but lower endemism and turnover than isolated catchments. Latitudinal gradients in richness and species traits in NA and Europe (Griffiths, 2006, 2010) are mainly due to differences in postglacial dispersal limitation (Griffiths, 2015). This paper investigates whether dispersal limitation also affects beta diversity and nestedness structure in freshwater fish, by examining the effects of realm shape, connectivity, glaciation, current climate and species traits on these properties.

Both NA (divided into Atlantic and Pacific realms, to the east and west of the Continental Divide) and Europe were affected by glaciation from the north but postglacial recolonization was influenced by differences in realm shape and connectivity (Griffiths, 2015). North America can be approximated by a triangle which tapers to the south (Fig. 1) with, in Atlantic NA, recolonization, mostly from the south, facilitated by north-south flowing rivers and the absence of significant mountain barriers. In contrast, Europe tapers to the southwest and is bounded by a southern marine barrier, with the unglaciated Iberian, Italian and Balkan/Greek peninsulas (Mediterranean regions) separated from the rest of Europe by mountain barriers. Postglacial recolonization of central and northern Europe was predominantly from the PontoCaspian region via the Danube (Banarescu, 1991). Large Ponto-Caspian rivers (Danube, Dnieper, Don, Volga) drain much of Europe, suggesting greater connectivity there than in the more isolated, east-west running, Pacific catchments. Hence, the current orientation and past connections of drainage channels indicate that connectivity for freshwater fish was greater in Atlantic NA than in Europe and least in Pacific NA.

I test four corollaries of the dispersal limitation hypothesis. First, if dispersal limitation is the main determinant of regional species composition, spatial separation between regions should predict beta diversity better than environmental (e.g. climatic or within-region heterogeneity) differences (Normand et al., 2006; Leprieur et al., 2009). Second, if dispersal is constrained by realm differences in colonization direction, climate and/or the habitat occupied, these factors should affect the shapes of species ranges (Svenning et al., 2011; Baselga et al., 2012c). Temperature and rainfall show similar strong latitudinal gradients in NA whereas in Europe trends are weaker and rainfall, unlike temperature, varies mainly in an east-west direction (Griffiths et al., 2014). Rosenfield (2002) showed that range shapes of river-dwelling fish in NA tended to show the north-south trend exhibited by large rivers whereas lake species had a more east-west bias, consistent with increased across-catchment connectivity from meltwater lakes formed along retreating glacial fronts. Hence, both climate and recolonization direction suggest that species ranges should show a more east-west bias in Europe than NA. Third, turnover should increase with decreasing dispersal opportunity and ability. Hence, turnover should be greatest in the Pacific and least in Atlantic NA, and less in glaciated areas: glaciation reworked long-established rivers by diversion, impoundment and the creation of new channels (Jacquemin \& Pyron, 2011), increasing across-catchment connectivity and facilitating recolonization. Post-glaciation, migratory fish, which are habitat generalists (Griffiths, 2006, 2010), should recolonize more rapidly and be less sensitive to barriers than non-migratory species. If connectivity limits recolonization, differences in beta values between 

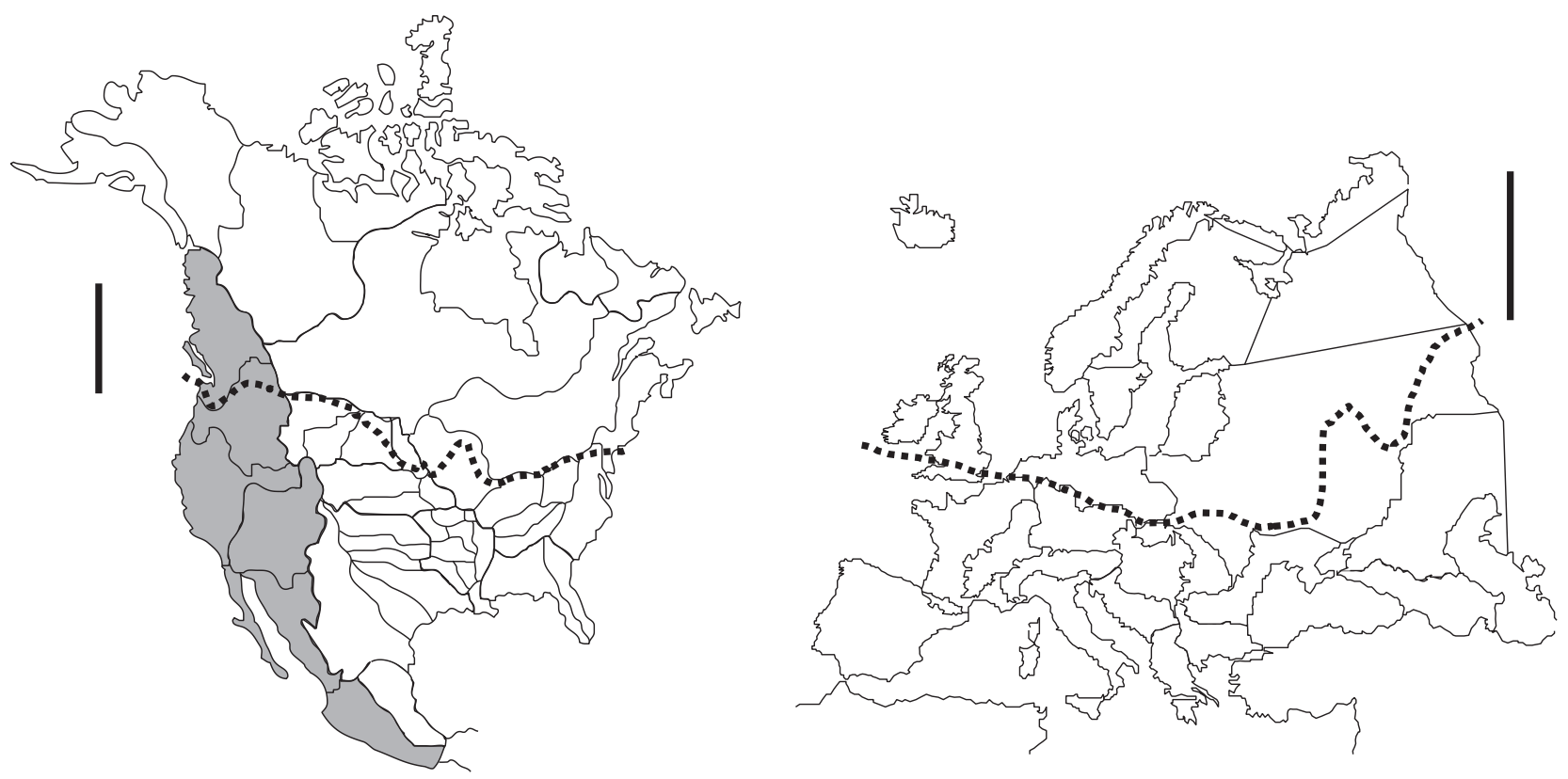

Figure 1 Regions of the North American Pacific (shaded) and Atlantic (left), and European (right), realms and the approximate limit of ice sheets at the Last Glacial Maximum (dotted lines). The thick vertical lines indicate $1000 \mathrm{~km}$. The regions are named in Appendix S1.

non-migrants and migrants should change more steeply with latitude in Europe than in Atlantic NA. Finally, differential colonization and extinction can generate nested matrices whereas matrices might be anti-nested from within-realm heterogeneity in species pools (Matthews et al., 2015). Idiosyncrasy, deviations from perfectly nested/anti-nested matrices by unexpected presences or absences, should increase with vagility (McAbendroth et al., 2005; Soininen \& Köngäs, 2012) and with declining connectivity (Atmar \& Patterson, 1993). Idiosyncratic species tend to have larger ranges, be more vagile and more generalist i.e. are potentially less dispersal-limited, while the homogenising effect of glaciation will reduce regional idiosyncrasy. Furthermore, migrants greater dispersal ability should result in fewer gaps within species ranges (Dullinger et al., 2012), and they will be less likely to show clustered (coincident) range boundaries arising from dispersal barriers (Presley \& Willig, 2010).

\section{MATERIALS AND METHODS}

Regional presence/absence datasets for native fish species found in freshwaters (Griffiths, 2015) were used. Regions were delimited by biogeographically relevant criteria: for example, the huge Hudson Bay region, despite comprising many drainage basins, acts as a single hydrological system (Crossman \& McAllister, 1986). The Mississippi and Danube basins were subdivided into drainage units (see Appendix S1 in Supporting Information). Richness and turnover analyses appear to be relatively robust to differences in regional area (Freijeiro \& Baselga, 2016). The species lists, updated from Griffiths (2006, 2010), were compiled, for NA from the
Isthmus of Tehuantepec northwards and for Europe west of the Urals and north of Turkey, from published information (Illies, 1978; Hocutt \& Wiley, 1986; Page \& Burr, 1991; Miller et al., 2005; Kottelat \& Freyhof, 2007). Iceland was omitted from the analysis since it is an isolated, oceanic, island with an impoverished fish fauna: all other (landbridge) islands were included. The Atlantic, Pacific and European realms have 743, 276 and 351 fish species, respectively. Analyses focus on Atlantic and European realms because the small number of Pacific realm regions (six, only one of which was glaciated) made region-focussed analyses unreliable.

Regions were identified as glaciated or unglaciated, depending on whether they were largely covered by ice at the Last Glacial Maximum. Using published sources (Hocutt \& Wiley, 1986; McDowall, 1988; Page \& Burr, 1991; Smith, 1991; Northcote, 1997; Maitland, 2000; Lucas \& Baras, 2001; Miller et al., 2005; Kottelat \& Freyhof, 2007; Chapman et al., 2012), FishBase (www.fishbase.org) and FishTraits (http:// www.fishtraits.info), species were categorized by (1) habitat preference, as riverine (found only in rivers), lacustrine (found only in lakes), or generalist (occurring in both habitats), (2) vagility, as migratory (migrating between sea and freshwater, along river channels or between rivers and lakes) or non-migratory, (3) colonization category, as non-colonizers (restricted to unglaciated areas) or recolonizers (occurring in both unglaciated and glaciated areas) and (4) distributional range, as endemic (found in only one region of a continent) or non-endemic. Note that these are nonexclusive categories: recolonizers tend to be habitat generalist migrants with large geographic ranges (Griffiths, 2006, 2010). 


\section{Data analysis}

\section{Beta metrics}

Overall dissimilarity, measured here by the Jaccard index $\left(D_{\text {jac }}\right)$, has replacement (turnover, Repl) and nestednessresultant (Nes) components i.e. $D_{\text {jac }}=$ Repl + Nes (Baselga, 2012). Multi-site and pairwise components (Repl $\beta_{\text {JTU }}, \beta_{\text {jtu }}$; Nes $\beta_{\text {JNE }}, \beta_{\text {jne, }}$ respectively) were calculated using the 'betapart' package (Baselga \& Orme, 2012) of R 3.1.2 (R Development Core Team, 2014): multi-site beta is the appropriate metric when estimating compositional variation over more than two sites. Multi-site beta values were calculated from 100 random samples taken from $50 \%$ of the regions in the smallest realm i.e. for three regions per realm. Within each realm, these beta metrics were calculated for all species, for non-migrants and for migrants. Beta values were compared across realms using the MRPP procedure in PCORD 6 (McCune \& Mefford, 2011).

\section{Distance predictors of beta}

The importance of geographic, climatic, and within-region heterogeneity variables in determining beta metrics was examined by regression, using standardized (mean $=0$, $\mathrm{SD}=1$ ) Euclidean distances so that coefficients were directly comparable. Pairwise beta values are not independent, so regressions used the multiple regression on distance matrices (MRM) procedure in the 'ecodist' package (Goslee \& Urban, 2007). Geographic distances were calculated between regional centroids. The factor scores for the first two principal component axes of climate and of regional variables were used when calculating climatic and within-region heterogeneity distances: the climate and regional predictors separately accounted for $75-86 \%$ of the variance within realms. Climatic variables for NA and Europe, for $1910-1950$ at a $0.5^{\circ}$ grid square resolution and compiled into regional values as described in Griffiths et al. (2014), were extracted from the climate dataset (CRU TS 1.2) at the University of East Anglia Climatic Research Unit (http://www.cru.uea.ac.uk).

Annual mean, maximum, minimum, and seasonal variation (SD of mean monthly values) in regional temperature and rainfall were the climate variables while $\log _{10}$ regional area, $\log _{10}$ elevational range, within-region variation in temperature and rainfall (SD of annual means over all $0.5^{\circ} \times 0.5^{\circ}$ grid squares comprising a region) were taken as indicators of within-region heterogeneity (Griffiths et al., 2014). The analysis was repeated for migrants and nonmigrants but the results were similar and are not shown.

\section{Range shapes}

Species range shapes were determined from regression of north-south on east-west extents, measured as distances along Universal Transverse Mercator grid lines between regional centroids: slopes $<1$ indicate ranges which are more extensive in an east-west direction. Regression slopes, across realms and across habitat preference, were compared by ANCOVA.

\section{Spatial trends in beta metrics}

Beta values are expected to vary with connectivity, glaciation, latitude and vagility. Realm, glaciation and vagility effects on multi-site Repl and Nes values were examined by ANOVA: three-way interaction terms were not significant but all other terms were included in the model and interactions tested using Tukey's HSD test. Within-realm species nestedness structures for glaciation and vagility effects were calculated, as described below, to ascertain whether the Nes values arose from nestedness or anti-nestedness.

To assess the contribution of vagility to beta diversity in unglaciated and glaciated areas, standardized pairwise beta values for non-migrants and migrants were regressed against beta values calculated across all species, with mean latitude as a covariate. To avoid confounding beta values of, for example, neighbouring mid-latitude regions with those of widely spaced regions of similar mean latitude but very different faunas, values were used only when both regions occurred within unglaciated areas or within glaciated areas.

\section{Nestedness structure}

Nestedness was measured using a nestedness metric (possible range $0-100$ ) based on paired overlap and decreasing fill (NODF) (Almeida-Neto \& Ulrich, 2011), with across-species and across-region components. The proportional row and column null model (Ulrich \& Gotelli, 2012) was used when testing but fixed-fixed models gave qualitatively similar results. Matrices were ordered by richness: this ordering correlates with latitude and vagility. Significance was assessed using $Z$-scores (deviation of observed NODF statistic from simulated mean/simulated standard deviation) as these are more or less independent of matrix fill, size, and shape (Almeida-Neto et al., 2008). Positive $Z$-scores indicate nestedness and negative ones anti-nestedness.

Anti-nestedness might result from high turnover or, as overlap declines to zero, segregated (compartmented) matrices (Ulrich \& Gotelli, 2013). To identify the pattern of antinestedness, $C$-scores, which measure species co-occurrences (Ulrich et al., 2009), were partitioned into segregation $\left(C_{\text {segr }}\right)$ and turnover $\left(C_{\text {turn }}\right)$ components for matrices ordered by reciprocal-averaging, using TuRnover 1.1 (Ulrich, 2012). To test if within-realm heterogeneity in species pools contributed to anti-nestedness, each realm was divided into two potentially more homogenous sub-realms and multi-site beta values and NODF scores for each sub-realm compared with whole realm values. Repl should increase and Nes decrease in the more isolated sub-realm but sub-realm nestedness should be less than for the whole realm. In Europe the rather different faunas of Mediterranean and non-Mediterranean Europe were identified as sub-realms $(134 / 238=56 \%$, 42 / 
$200=21 \%$ endemic species, respectively). Atlantic regions from the Mississippi Basin northwards, and for which there is strong evidence for marked postglacial species interchange (Crossman \& McAllister, 1986) were treated as one subrealm while the remaining regions, to the south and west of the Mississippi (north and south Western Gulf, Rio Grande and Atlantic Mexico) and which probably contributed little to postglacial recolonization, constituted the other sub-realm $(173 / 551=31 \%, 153 / 297=52 \%$ endemic $)$.

Idiosyncrasy values (DeltaC) were determined using the NODF temperature option. The effects of realm and glaciation on regional idiosyncrasy values were examined by ANOVA. Species with DeltaC scores below -0.1 were categorized as idiosyncratic.

The greater dispersal abilities of migratory species should result in greater coherence (fewer gaps within species ranges) than in non-migrants, which are more likely to show clustered boundary distributions across species from a greater sensitivity to barriers. Coherence was measured by embedded absences (EmbAbs) and boundary clustering by Morisita's index, using the Turnover program (Ulrich, 2012) on ordinated matrices, with $z$-scores determined using the proportional-proportional null model (to be consistent with the nestedness metric).

\section{RESULTS}

\section{Beta diversity}

\section{Distance predictors of beta}

Geographic distance was a stronger predictor of beta values than climatic and within-region heterogeneity distances in the Atlantic NA and Europe, though none of the variables was a strong predictor in Europe (Table 1). While geographic distance was correlated with climatic and regional distances (Atlantic $r=0.65, r=0.17$; Europe $r=0.56$, $r=0.24$, respectively, all $P<0.001$ ) variance partitioning showed that geographic distance accounted for $80 \%$ of explained variance and $94 \%$ of the unshared variance in Repl (means over realms): the corresponding figures for Nes were $45 \%$ and $54 \%$.

\section{Range shapes}

Species range shapes differed across realms: in Europe the slope of north-south, east-west range extents was significantly less than in Atlantic NA $(0.71 \pm 0.02,0.86 \pm 0.02$, respectively; slopes $\left.F_{1,1088}=30.14, \quad P<0.001\right)$, indicating that ranges in Europe extend more in an east-west direction (see Appendix S2). Range shape varied significantly with habitat in Atlantic NA, extending more in an east-west direction in lake than in river species, but only marginally so in Europe (slopes $F_{1,737}=15.95, P<0.001 ; F_{1,347}=3.67$, $P=0.06$, respectively; see Appendix S2): slopes differed across realms only for river species $\left(F_{1,678}=55.50\right.$, $P<0.001)$.

\section{Spatial trends in beta metrics}

Beta metrics varied largely as predicted. Repl was least and Nes greatest in the most connected, Atlantic, realm (Table 2). Repl comprised $82 \%, 89 \%, 94 \%$ of $D_{\text {jac }}$ for Atlantic, European and Pacific realms and increased as connectivity declined $\left(F_{1,297}=101.55, P<0.001\right)$. Apart from no difference in Repl between Atlantic NA and Europe, all factors (realm, glaciation, vagility) and interactions were significant predictors of Repl and Nes (Table 3). In Europe turnover was greater and nestedness-resultant dissimilarity less in unglaciated areas and in non-migrants, as expected. In the better-connected Atlantic realm Repl did not differ with glaciation or migration category but Nes was less in unglaciated areas and, unexpectedly, greater in non-migrants. All but one $\mathrm{NODF}_{\text {spp }} Z$ scores were significantly negative, indicating anti-nestedness. As expected from connectivity, the difference in beta values between non-migrants and migrants changed more steeply with latitude in Europe than in Atlantic NA (difference in Repl slopes $-0.015 \pm 0.002$, $-0.004 \pm 0.001, \quad F_{1,591}=21.63, \quad P<0.001 ;$ Nes difference $0.009 \pm 0.002, \quad 0.005 \pm 0.001, \quad F_{1,591}=4.92, \quad P<0.05$ for European and Atlantic realms, respectively).

Repl decreased (Spearman $r_{\mathrm{s}}=-0.20,-0.31, P<0.001$ ) and Nes increased $\left(r_{\mathrm{s}}=0.11,0.26, P<0.001\right)$ with latitude in Atlantic NA and Europe (Fig. 2). In unglaciated areas non-migrants were the main determinants of variation in

Table 1 Regression coefficients from multiple regressions of (square-root transformed) standardized geographic, climatic, and withinregion heterogeneity Euclidean distances against pairwise beta metrics for freshwater fish in Atlantic and European realms.

\begin{tabular}{|c|c|c|c|c|c|c|}
\hline \multirow[b]{2}{*}{ Distance variable } & \multicolumn{3}{|l|}{ Atlantic } & \multicolumn{3}{|l|}{ Europe } \\
\hline & $D_{\mathrm{jac}}$ & Repl & Nes & $D_{\text {jac }}$ & Repl & Nes \\
\hline Geographic & $0.125^{\star \star \star}$ & $0.142^{\star * *}$ & $0.006^{*}$ & $0.032^{\star * *}$ & $0.030^{* * *}$ & -0.001 \\
\hline Climatic & $0.018^{\star * *}$ & $0.019^{\star * *}$ & 0.002 & -0.002 & -0.009 & -0.003 \\
\hline Within-region heterogeneity & $-0.008^{\star * *}$ & 0.003 & 0.002 & -0.003 & -0.006 & -0.001 \\
\hline$R^{2}$ & 0.42 & 0.29 & 0.001 & 0.04 & 0.02 & 0.002 \\
\hline
\end{tabular}

$* * * P<0.001, * P<0.05$.

$D_{\text {jac }}=$ Jaccard distance; Repl $=$ replacement dissimilarity; Nes $=$ nested-resultant dissimilarity. 
overall Repl and Nes whereas migrants were more important in glaciated areas (see Appendix S3).

\section{Nestedness structure}

Overall NODF scores were low, ranging from 16 to 25 across realms (Table 2). All species (Table 2) and migratory categories were anti-nested, but migrants had higher NODF scores than non-migrants (mean NODF 46.0, 17.4, Table 4). Turnover, not segregation, was the dominant component of $C$-score values (Table 4): $C_{\text {turn }}$ increased with decreasing connectivity across realms and was greater for migratory than for non-migratory species. More isolated sub-realms (southwest Atlantic NA and Mediterranean Europe) showed greater species turnover, less nestedness-resultant dissimilarity, and more marked idiosyncrasy, relative to more connected regions (see Appendix S3). Only southwest Atlantic NA was anti-nested.
Regional idiosyncrasy declined as connectivity increased across realms, and was greater in unglaciated regions (Fig. 3): ANOVA $R^{2}=0.65$, realms $F_{2,65}=10.97$ (least squares means Atlantic -0.10, Europe -1.60 , Pacific -5.22), glaciation category $F_{1,65}=27.72$, interaction $F_{2,65}=10.37$, all $P<0.001$. Migrants were significantly more likely to be idiosyncratic than non-migrants (Table 4).

All species showed fewer gaps within species ranges than expected (EmbAbs, Table 4). Atlantic and European nonmigrants had clustered range boundaries but migrants did not. Matrix fill was significantly greater for migrants than non-migrants in all realms, reflecting their greater range sizes.

\section{DISCUSSION}

The dominance of geographic distance as a predictor of beta diversity, the variation in beta values with connectivity, the

Table 2 Multi-site beta ( \pm 1 SE), NODF and C-score values for the three realms for freshwater fish in North America and Europe.

\begin{tabular}{lllllllll}
\hline Realm & Number of regions & $D_{\text {jac }}$ & Repl & Nes & NODF $(Z)$ & NODF $_{\text {spp }}(Z)$ & NODF $_{\text {reg }}(Z)$ & $C$-score $(Z)$ \\
\hline Atlantic & 42 & $0.825 \pm 0.010$ & $0.683 \pm 0.016 \mathrm{a}$ & $0.142 \pm 0.009$ & $24.79(-\mathbf{3 . 5 3})$ & $24.73(-\mathbf{3 . 5 2})$ & $43.63(-\mathbf{3 . 8 8})$ & $0.012(1.53)$ \\
Europe & 23 & $0.787 \pm 0.009$ & $0.704 \pm 0.013 \mathrm{a}$ & $0.084 \pm 0.006$ & $23.58(-\mathbf{5 . 1 3})$ & $23.46(-\mathbf{5 . 1 5})$ & $52.16(-0.49)$ & $0.019(\mathbf{4 . 3 8})$ \\
Pacific & 6 & $0.900 \pm 0.007$ & $0.851 \pm 0.011$ & $0.049 \pm 0.004$ & $16.50(-\mathbf{3 . 8 7})$ & $16.49(-\mathbf{3 . 8 7})$ & $25.43(0.18)$ & $0.076(\mathbf{2 . 7 9})$ \\
\hline
\end{tabular}

Realms with the same letter are not significantly different.

Standardized effect size $(Z)$ values in boldface indicate differences from the null hypothesis of no nestedness or checkerboard effect at $P<0.05$.

Table 3 Means squares and the least squares adjusted means from ANOVAs of multi-site Repl and Nes values and the corresponding $Z$ scores for species nestedness structure for freshwater fish in North America and Europe.

\begin{tabular}{|c|c|c|c|c|c|c|c|}
\hline & d.f. & Repl MS & Nes MS & Factors & Repl means & Nes means & $Z\left(\mathrm{NODF}_{\mathrm{spp}}\right)$ \\
\hline \multirow[t]{2}{*}{ Realm } & \multirow[t]{2}{*}{1} & \multirow[t]{2}{*}{0.049} & \multirow[t]{2}{*}{$0.615^{\star * *}$} & Atlantic & $0.597 a$ & 0.198 & -3.52 \\
\hline & & & & Europe & $0.581 \mathrm{a}$ & 0.143 & -5.15 \\
\hline \multirow[t]{2}{*}{ Glaciation category } & \multirow[t]{2}{*}{1} & \multirow[t]{2}{*}{$0.723^{* * *}$} & \multirow[t]{2}{*}{$1.154^{\star * *}$} & Unglaciated & 0.619 & 0.132 & \\
\hline & & & & Glaciated & 0.559 & 0.208 & \\
\hline \multirow[t]{2}{*}{ Migration category } & \multirow[t]{2}{*}{1} & \multirow[t]{2}{*}{$3.259^{* * *}$} & \multirow[t]{2}{*}{$0.101^{\star *}$} & Non-migrant & 0.653 & 0.182 & \\
\hline & & & & Migrant & 0.525 & 0.159 & \\
\hline \multirow[t]{4}{*}{ Realm $\times$ Glaciation } & \multirow[t]{4}{*}{1} & \multirow[t]{4}{*}{$0.635^{\star * *}$} & \multirow[t]{4}{*}{$0.209^{* * *}$} & Unglaciated Atlantic & $0.599 \mathrm{a}$ & $0.144 \mathrm{ab}$ & -3.29 \\
\hline & & & & Glaciated Atlantic & $0.595 \mathrm{a}$ & 0.252 & -0.59 \\
\hline & & & & Unglaciated Europe & $0.640 \mathrm{a}$ & $0.121 b$ & -3.76 \\
\hline & & & & Glaciated Europe & 0.523 & $0.164 \mathrm{a}$ & -4.12 \\
\hline \multirow[t]{4}{*}{ Realm $\times$ migration } & \multirow[t]{4}{*}{1} & \multirow[t]{4}{*}{$4.170^{* * *}$} & \multirow[t]{4}{*}{$1.792^{* * *}$} & Non-migrant, Atlantic & $0.589 a$ & 0.257 & -3.12 \\
\hline & & & & Migrant, Atlantic & $0.605 \mathrm{a}$ & 0.140 & -3.01 \\
\hline & & & & Non-migrant, Europe & 0.717 & 0.107 & -3.21 \\
\hline & & & & Migrant, Europe & 0.445 & 0.179 & -2.79 \\
\hline \multirow[t]{4}{*}{ Glaciation $\times$ migration } & \multirow[t]{4}{*}{1} & \multirow[t]{4}{*}{$1.992^{* * *}$} & \multirow[t]{4}{*}{$1.368^{\star * *}$} & Glaciated, Migrant & $0.545 \mathrm{ab}$ & $0.156 \mathrm{a}$ & \\
\hline & & & & Unglaciated, Migrant & $0.506 \mathrm{a}$ & $0.163 a$ & \\
\hline & & & & Glaciated, non-migrant & $0.573 b$ & 0.261 & \\
\hline & & & & Unglaciated, non-migrant & 0.733 & 0.102 & \\
\hline Error & 793 & 0.032 & 0.013 & & & & \\
\hline$R^{2}$ & & 0.30 & 0.33 & SE & 0.013 & 0.008 & \\
\hline
\end{tabular}

$* * * P<0.001, * * P<0.01$

Within each category, values with the same letter are not significantly different (Tukey's HSD test).

$Z$ scores in boldface are statistically significant. 
Figure 2 Repl (circles) and Nes (triangles) values for freshwater fish as a function of mean latitude for (a) Atlantic and (b) European realms. LOWESS smoothed lines are shown.

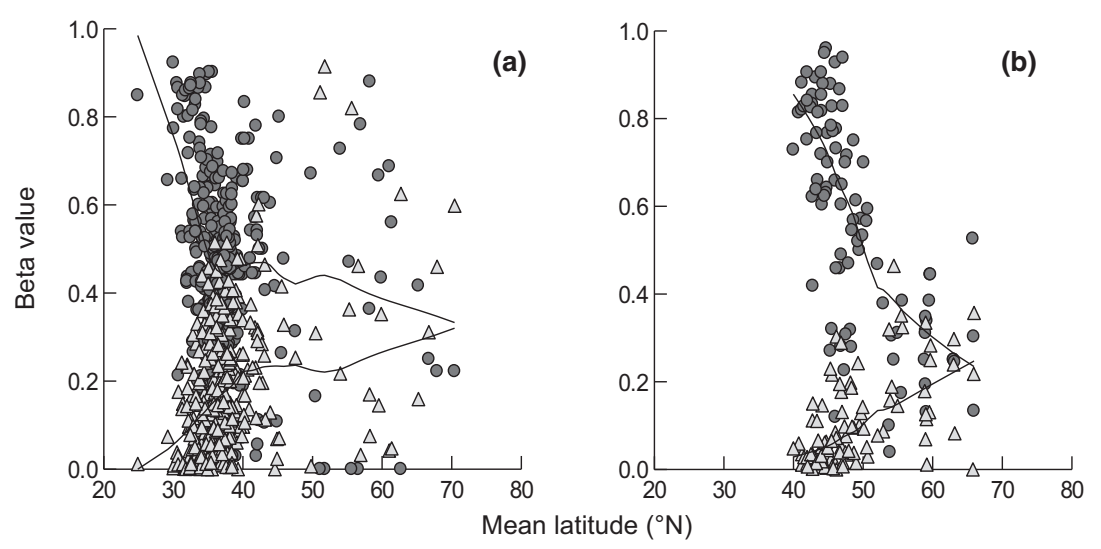

latitudinal trends in beta components and the greater idiosyncrasy of migratory species strongly suggest that variation in freshwater fish species composition at the regional scale is due mainly to differences in postglacial dispersal ability and opportunity. An analysis of latitudinal richness gradients across the three realms reached a similar conclusion (Griffiths, 2015).

The greater contribution of geographic than climate or within-region heterogeneity distances to predicting beta diversity points to dispersal limitation as being more influential than niche difference and within-region features for freshwater fish. Some studies support this ranking (Leprieur et al., 2009; Qian et al., 2009; Astorga et al., 2012) whereas others (Bjorholm et al., 2008; Grönroos et al., 2013) have found stronger environmental effects, their importance varying with the scale of investigation (Keil et al., 2012) and perhaps vagility (Steinitz et al., 2006). Spatial, climatic and regional heterogeneity factors predicted catchment-scale beta diversity in freshwater fish in Europe and NA (Leprieur et al., 2009; Baselga \& Leprieur, 2015). Leprieur et al. (2009) showed that mountain barriers in Europe had the strongest effect on turnover. Baselga \& Leprieur (2015) found that past and present climatic factors had the largest effect although geographic distance was also important: the contrast with my results possibly results from the larger scale of this analysis.

Baselga et al. (2012c), examining a variety of terrestrial vertebrate and plant groups globally, found a predominantly east-west bias in range shape, and concluded that climate and particularly dispersal limitation affected range shape. Spatially constrained dispersal has been demonstrated in mammals (Svenning et al., 2011; Wen et al., 2016). The greater east-west bias in European fish species range shapes is consistent with spatially constrained dispersal but also with a climate effect. Rosenfield (2002) found that range shapes of river-dwelling fish species in NA tended to show the northsouth trend exhibited by large rivers whereas lake species had a more east-west bias, consistent with increased connectivity from meltwater along retreating glacial fronts. My results support this conclusion in Atlantic NA, but habitat had no clear effect on range shape in Europe. However, the difference between realms in range shape for river species probably reflects differences in catchment shape as only $16 \%$ of riverine species have recolonized glaciated regions.

Beta diversity varies with the potential for species exchange between regions. Low connectivity favours turnover: the least connected, Pacific, realm showed the greatest level of replacement across regions and replacement there was the most dominant component of beta diversity. As connectivity decreases across realms, non-migrants are less likely to recolonize postglaciation and migrants form an increasing percentage of the fauna i.e. species richness and turnover should decline and nestedness-resultant dissimilarity increase. The dominance of turnover, particularly in unglaciated areas, in determining spatial variation in fish species composition results from the importance of non-migratory (Griffiths, 2015) species (\% non-migrants in unglaciated areas; Atlantic 87\%, Europe $80 \%$ ). Most studies report turnover as larger than nestednessresultant dissimilarity, but their importance varies spatially (Baselga, 2010; Leprieur et al., 2011; Baselga et al., 2012a; Dobrovolski et al., 2012). As expected, turnover is less in glaciated (northern) areas and in migrants (Table 3; Baselga et al., 2012a; Dobrovolski et al., 2012; Aranda et al., 2013). Freshwater fish replacements declined to the north in both realms. Similar latitudinal trends have been reported in other taxa (Baselga, 2010; Baselga et al., 2012a). In line with these findings, Leprieur et al. (2011) found a negative correlation between replacement and past glacial conditions for freshwater fish globally. Baselga (2010) noted that higher turnover in southern regions in his study system was associated with endemism. My results are consistent with greater environmental heterogeneity across southern regions, favouring smaller range sizes (Rapoportt's Rule, Griffiths, 2010; Blanchet et al., 2013), and thus greater endemism and more replacements.

Direct measures of nestedness showed all species, and non-migratory and migratory species, to be anti-nested (segregated) at the realm scale. Although they did find segregation to be common, Ulrich \& Gotelli (2013) reported that $<1 \%$ of 195 biogeographic-scale studies showed anti-nestedness, contrary with my results and those of Matthews et al. (2015). High turnover and non-inclusive sets of species can generate anti-nestedness (Almeida-Neto et al., 2007). Antinestedness in freshwater fish was largely due to high turnover (Table 4; for realms, 89-99\% of $C$-scores were a consequence 


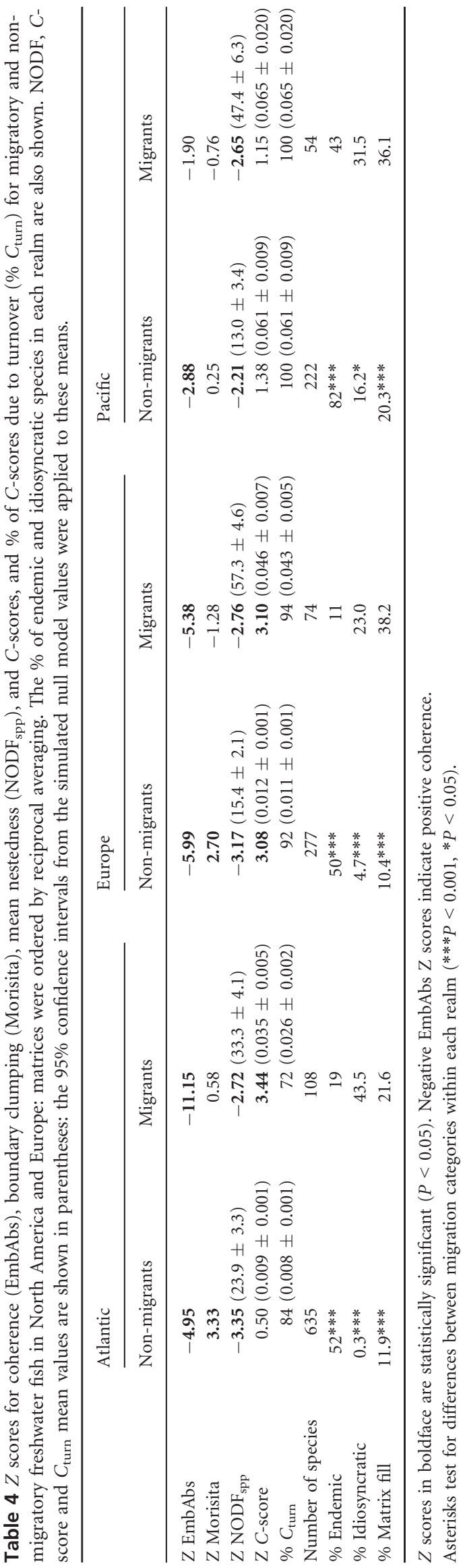

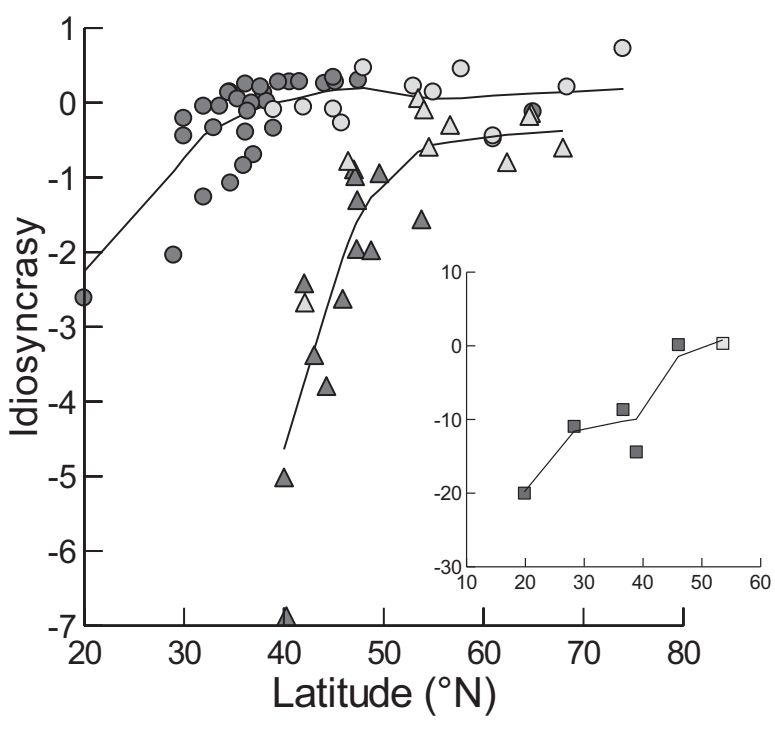

Figure 3 Regional idiosyncrasy (DeltaC) values for freshwater fish vary with latitude in Atlantic (circles) and European (triangles) realms. Pacific values (inset) are shown at a different scale. Dark fill $=$ unglaciated regions, light fill $=$ glaciated regions. LOWESS smoothed lines are shown.

of replacements and none was due exclusively to segregation). Non-inclusive species groupings, from speciation or regions with different faunal origins/histories, also contributed to anti-nestedness. Levels of endemism were higher for non-migrants than migrants (Table 4), from speciation in Atlantic NA and extinction in Pacific NA (Smith et al., 2010). The characteristic fish faunas of the Iberian, Italian and Balkan/Greek peninsulas, which were established mainly in the late Miocene (Bianco, 1990), have a larger percentage of endemic (mean regional values, $33 \%$ vs. $3 \%$ ) and nonmigratory species (60\% vs. $34 \%)$ than the rest of Europe. Hence, these Mediterranean faunas are not typical of the rest of Europe (Banarescu, 1991; Reyjol et al., 2007) and thus contribute to anti-nestedness and to regional idiosyncrasy. Similarly, anti-nestedness only occurred in the relatively poorly connected southwest Atlantic regions (30\% vs. $2 \%$ endemics, $83 \%$ vs. $64 \%$ non-migrants). These results support the beta diversity analysis for the importance of turnover in determining spatial variation in species composition and reinforce the need to examine a range of metrics before the factors determining nestedness structure can be identified (Ulrich \& Gotelli, 2013).

Dispersal/connectivity and niche effects can account for biogeographic variation in metacommunity structure (Presley \& Willig, 2010; Henriques-Silva et al., 2013; Heino \& Alahuhta, 2015). Migratory fish occupied more space more completely (high matrix fill, strong range coherence), as a consequence of their greater dispersal ability. Non-migrants should be more limited than migrants by dispersal opportunity and consequently show clustered range boundaries, although clustering could also result from species with similar niche requirements. The greater contribution of geographic compared to 
environmental distances as a predictor of beta values for migrant and non-migrant species (results similar to those in Table 1) favours a dispersal-limitation explanation.

In all realms idiosyncrasy tended to be greatest in southern, unglaciated, regions, and increased with declining connectivity across realms. European and Pacific values support the notion that regions providing limited dispersal opportunity are more likely to generate unexpected distributional absences but the most idiosyncratic Atlantic regions (Atlantic Mexico, Rio Grande; Cumberland, Tennessee, Gulf Florida, Central Appalachia) are still connected, or were in the recent past (Hocutt \& Wiley, 1986). Idiosyncratic species have been shown to be more widely distributed and vagile than more nested species (McAbendroth et al., 2005; Heino et al., 2009; Soininen \& Köngäs, 2012; Batzer \& Ruhí, 2013) and my results are consistent with that conclusion.

\section{CONCLUSIONS}

This study provides strong evidence that beta diversity and nestedness structure in freshwater fish in NA and Europe are a consequence of post-glacial differences in dispersal opportunity and dispersal ability. However, many studies have found stronger effects of contemporary conditions. This may be due to differences in vagility between the taxa analysed and/or in dispersal opportunity. Turnover increases with declining vagility (Qian, 2009; Baselga et al., 2012b; Carvalho \& Cardoso, 2014) so, within realms, the absence of highly vagile taxa from an area is more likely to be determined by environmental conditions (Steinitz et al., 2006; Astorga et al., 2012). Most freshwater fish are confined to networks which are stable over historically long periods, and across catchment dispersal opportunities are infrequent relative to terrestrial species or aquatic species with a terrestrial stage. The dominance of turnover in determining spatial variation in fish species composition results from the dominance of nonmigratory species in unglaciated areas.

This study highlights the need to use multiple metrics when identifying the structure of species assemblages. Nestedness-resultant dissimilarity does not distinguish between nestedness and anti-nestedness and, as pointed out by others (Almeida-Neto et al., 2007; Matthews et al., 2015), anti-nestedness can arise in a variety of ways.

\section{ACKNOWLEDGEMENTS}

I thank Mário Almeida-Neto and Werner Ulrich for guidance on nestedness analyses, and Mário Almeida-Neto, Fabien Leprieur and the referees for helpful comments on earlier drafts.

\section{REFERENCES}

Almeida-Neto, M. \& Ulrich, W. (2011) A straightforward computational approach for measuring nestedness using quantitative matrices. Environmental Modelling \& Software, 26, 173-178.

Almeida-Neto, M., Guimarães, P.R. \& Lewinsohn, T.M. (2007) On nestedness analyses: rethinking matrix temperature and anti-nestedness. Oikos, 116, 716-722.

Almeida-Neto, M., Guimarães, P., Guimarães, P.R., Loyola, R.D. \& Ulrich, W. (2008) A consistent metric for nestedness analysis in ecological systems: reconciling concept and measurement. Oikos, 117, 1227-1239.

Aranda, S.C., Gabriel, R., Borges, P.A.V., Santos, A.M.C., Hortal, J., Baselga, A. \& Lobo, J.M. (2013) How do different dispersal modes shape the species-area relationship? Evidence for between-group coherence in the Macaronesian flora. Global Ecology and Biogeography, 22, 483-493.

Astorga, A., Oksanen, J., Luoto, M., Soininen, J., Virtanen, R. \& Muotka, T. (2012) Distance decay of similarity in freshwater communities: do macro- and microorganisms follow the same rules? Global Ecology and Biogeography, 21, 365-375.

Atmar, W. \& Patterson, B.D. (1993) The measure of order and disorder in the distribution of species in fragmented habitat. Oecologia, 96, 373-382.

Banarescu, P. (1991) Zoogeography of fresh waters. Volume 2. Distribution and dispersal of freshwater animals in North America and Eurasia. Aula-Verlag, Wiesbaden.

Baselga, A. (2010) Partitioning the turnover and nestedness components of beta diversity. Global Ecology and Biogeography, 19, 134-143.

Baselga, A. (2012) The relationship between species replacement, dissimilarity derived from nestedness, and nestedness. Global Ecology and Biogeography, 21, 1223-1232.

Baselga, A. \& Leprieur, F. (2015) Comparing methods to separate components of beta diversity. Methods in Ecology and Evolution, 6, 1069-1079.

Baselga, A. \& Orme, C.D.L. (2012) betapart: an R package for the study of beta diversity. Methods in Ecology and Evolution, 3, 808-812.

Baselga, A., Gómez-Rodríguez, C. \& Lobo, M. (2012a) Historical legacies in world amphibian diversity revealed by the turnover and nestedness components of beta diversity. PLOS ONE, 7, e32341.

Baselga, A., Lobo, J.M., Svenning, J.-C., Aragón, P. \& Araújo, M.B. (2012b) Dispersal ability modulates the strength of the latitudinal richness gradient in European beetles. Global Ecology and Biogeography, 21, 1106-1113.

Baselga, A., Lobo, J.M., Svenning, J.-C. \& Araújo, M.B. (2012c) Global patterns in the shape of species geographical ranges reveal range determinants. Journal of Biogeography, 39, 760-771.

Batzer, D.P. \& Ruhí, A. (2013) Is there a core set of organisms that structure macroinvertebrate assemblages in freshwater wetlands? Freshwater Biology, 58, 1647-1659.

Bianco, P.G. (1990) Potential role of the palaeohistory of the Mediterranean and Paratethys basins on the early dispersal of Euro-Mediterranean freshwater fishes. Ichthyological Explorations in Freshwaters, 1, 167-184. 
Bjorholm, S., Svenning, J.-C., Skov, F. \& Balslev, H. (2008) To what extent does Tobler's 1st law of geography apply to macroecology? A case study using American palms (Arecaceae). BMC Ecology, 8, 11.

Blanchet, S., Reyjol, Y., April, J., Mandrak, N.E., Rodríguez, M.A., Bernatchez, L. \& Magnan, P. (2013) Phenotypic and phylogenetic correlates of geographic range size in Canadian freshwater fishes. Global Ecology and Biogeography, 22, 1083-1094.

Carvalho, J.C. \& Cardoso, P. (2014) Drivers of beta diversity in Macaronesian spiders in relation to dispersal ability. Journal of Biogeography, 41, 1859-1870.

Chapman, B.B., Skov, C., Hulthén, K., Brodersen, J., Nilsson, P.A., Hansson, L.-A. \& Brönmark, C. (2012) Partial migration in fishes: definitions, methodologies and taxonomic distribution. Journal of Fish Biology, 81, 479-499.

Crossman, E.J. \& McAllister, D.E. (1986) Zoogeography of the freshwater fishes of the Hudson Bay drainage, Ungava Bay and the Arctic Archipelago. The zoogeography of North American freshwater fishes (ed. by C.H. Hocutt and E.O. Wiley), pp. 53-104. J Wiley \& Sons, New York.

Dapporto, L., Fattorini, S., Vod, R., Dinc, V. \& Vila, R. (2014) Biogeography of western Mediterranean butterflies: combining turnover and nestedness components of faunal dissimilarity. Journal of Biogeography, 41, 16391650.

Dias, M.S., Oberdorff, T., Hugueny, B., Leprieur, F., Jézéquel, C., Cornu, J.-F., Brosse, S., Grenouillet, G., Tedesco, P.A. \& Anderson, M. (2014) Global imprint of historical connectivity on freshwater fish biodiversity. Ecology Letters, 17, 1130-1140.

Dobrovolski, R., Melo, A.S., Cassemiro, F.A.S. \& Diniz-Filho, J.A.F. (2012) Climatic history and dispersal ability explain the relative importance of turnover and nestedness components of beta diversity. Global Ecology and Biogeography, 21, 191-197.

Dullinger, S., Willner, W., Plutzar, C., Englisch, T., SchrattEhrendorfer, L., Moser, D., Ertl, S., Essl, F. \& Niklfeld, H. (2012) Post-glacial migration lag restricts range filling of plants in the European Alps. Global Ecology and Biogeography, 21, 829-840.

Freijeiro, A. \& Baselga, A. (2016) Spatial and environmental correlates of species richness and turnover patterns in European cryptocephaline and chrysomeline beetles. ZooKeys, 597, 81-99.

Goslee, S.C. \& Urban, D.L. (2007) The ecodist package for dissimilarity-based analysis of ecological data. Journal of Statistical Software, 22, 1-19.

Griffiths, D. (2006) Pattern and process in the ecological biogeography of European freshwater fish. Journal of Animal Ecology, 75, 734-751.

Griffiths, D. (2010) Pattern and process in the distribution of North American freshwater fish. Biological Journal of the Linnean Society, 100, 46-61.

Griffiths, D. (2015) Connectivity and vagility determine spatial richness gradients and diversification of freshwater fish in North America and Europe. Biological Joumal of the Linnean Society, 116, 773-786.

Griffiths, D., McGonigle, C. \& Quinn, R. (2014) Climate and species richness patterns in freshwater fish in North America and Europe. Journal of Biogeography, 41, 452-463.

Grönroos, M., Heino, J., Siqueira, T., Landeiro, V.L., Kotanen, J. \& Bini, L.M. (2013) Metacommunity structuring in stream networks: roles of dispersal mode, distance type, and regional environmental context. Ecology and Evolution, 3, 4473-4487.

Heino, J. \& Alahuhta, J. (2015) Elements of regional beetle faunas: faunal variation and compositional breakpoints along climate, land cover and geographical gradients. Journal of Animal Ecology, 84, 427-441.

Heino, J., Mykrä, H. \& Muotka, T. (2009) Temporal variability of nestedness and idiosyncratic species in stream insect assemblages. Diversity and Distributions, 15, 198-206.

Henriques-Silva, R., Lindo, Z. \& Peres-Neto, P.R. (2013) A community of metacommunities: exploring patterns in species distributions across large geographical areas. Ecology, 94, 627-639.

Hocutt, C.H. \& Wiley, E.O. (eds) (1986) The zoogeography of North American freshwater fishes. J Wiley \& Sons, New York.

Illies, J. (1978) Limnofauna Europaea. Gustav Fischer Verlag, Stuttgart.

Jacquemin, S.J. \& Pyron, M. (2011) Impacts of past glaciation events on contemporary fish assemblages of the Ohio River basin. Journal of Biogeography, 38, 982-991.

Keil, P., Schweiger, O., Kühn, I., Kunin, W.E., Kuussaari, M., Settele, J., Henle, K., Brotons, L., Pe'er, G., Lengyel, S., Moustakas, A., Steinicke, H. \& Storch, D. (2012) Patterns of beta diversity in Europe: the role of climate, land cover and distance across scales. Journal of Biogeography, 39, 1473-1486.

Kottelat, M. \& Freyhof, J. (2007) Handbook of European freshwater fishes. Kottelat \& Freyhof, Cornol \& Berlin.

Leprieur, F., Olden, J.D., Lek, S. \& Brosse, S. (2009) Contrasting patterns and mechanisms of spatial turnover for native and exotic freshwater fish in Europe. Journal of Biogeography, 36, 1899-1912.

Leprieur, F., Tedesco, P.A., Hugueny, B., Beauchard, O., Dürr, H.H., Brosse, S. \& Oberdorff, T. (2011) Partitioning global patterns of freshwater fish beta diversity reveals contrasting signatures of past climate changes. Ecology Letters, 14, 325-334.

Lucas, M.C. \& Baras, E. (2001) Migration of freshwater fishes. Blackwell Science, Oxford.

Maitland, P.S. (2000) Guide to freshwater fish of Britain and Europe. Hamlyn, London.

Matthews, T.J., Cottee-Jones, H.E.W. \& Whittaker, R.J. (2015) Quantifying and interpreting nestedness in habitat islands: a synthetic analysis of multiple datasets. Diversity and Distributions, 21, 392-404.

McAbendroth, L., Foggo, A., Rundle, S.D. \& Bilton, D.T. (2005) Unravelling nestedness and spatial pattern in pond assemblages. Journal of Animal Ecology, 74, 41-49. 
McCune, B. \& Mefford, M.J. (2011) PC-ORD. Multivariate Analysis of Ecological Data. MjM Software, Gleneden Beach, Oregon, U.S.A.

McDowall, R.M. (1988) Diadromy in fishes. Croom Helm, London.

Miller, R.R., Minckley, W.L. \& Norris, S.M. (2005) Freshwater fishes of Mexico. University of Chicago Press, Chicago.

Normand, S., Vormisto, J., Svenning, J.-C., Grández, C. \& Balslev, H. (2006) Geographical and environmental controls of palm beta diversity in paleo-riverine terrace forests in Amazonian Peru. Plant Ecology, 186, 161-176.

Northcote, T.G. (1997) Potamodromy in Salmonidae - living and moving in the fast lane. North American Journal of Fisheries Management, 17, 1029-1045.

Page, L.M. \& Burr, B.M. (1991) A field guide to freshwater fishes of North America north of Mexico. Houghton Mifflin Company, Boston.

Presley, S.J. \& Willig, M.R. (2010) Bat metacommunity structure on Caribbean islands and the role of endemics. Global Ecology and Biogeography, 19, 185-199.

Qian, H. (2009) Beta diversity in relation to dispersal ability for vascular plants in North America. Global Ecology and Biogeography, 18, 327-332.

Qian, H., Badgley, C. \& Fox, D.L. (2009) The latitudinal gradient of beta diversity in relation to climate and topography for mammals in North America. Global Ecology and Biogeography, 18, 111-122.

R Development Core Team (2014) R: A language and environment for statistical computing. $\mathrm{R}$ Foundation for Statistical Computing, Vienna, Austria.

Reyjol, Y., Hugueny, B., Pont, D., Bianco, P.G., Beier, U., Caiola, N., Casals, F., Cowx, I., Economou, A., Ferreira, T., Haidvogl, G., Noble, R., de Sostoa, A., Vigneron, T. \& Virbickas, T. (2007) Patterns of species richness and endemism of European freshwater fish. Global Ecology and Biogeography, 16, 65-75.

Rosenfield, J.A. (2002) Pattern and process in the geographical ranges of freshwater fishes. Global Ecology and Biogeography, 11, 323-332.

Si, X., Baselga, A. \& Ding, P. (2015) Revealing beta-diversity patterns of breeding bird and lizard communities on inundated land-bridge islands by separating the turnover and nestedness components. PLoS ONE, 10, e0127692.

Smith, G.R., Badgley, C., Eiting, T.P. \& Larson, P.S. (2010) Species diversity gradients in relation to geological history in North American freshwater fishes. Evolutionary Ecology Research, 12, 693-726.

Smith, R.J.F. (1991) Social behaviour, homing and migration. Cyprinid fishes: systematics, biology and exploitation (ed. by I.J. Winfield and J.S. Nelson), pp. 509-529. Chapman \& Hall, London.
Soininen, J. \& Köngäs, P. (2012) Analysis of nestedness in freshwater assemblages - patterns across species and trophic levels. Freshwater Science, 31, 1145-1155.

Steinitz, O., Heller, J., Tsoar, A., Rotem, D. \& Kadmon, R. (2006) Environment, dispersal and patterns of species similarity. Journal of Biogeography, 33, 1044-1054.

Svenning, J.-C., Fløjgaard, C. \& Baselga, A. (2011) Climate, history and neutrality as drivers of mammal beta diversity in Europe: insights from multiscale deconstruction. Journal of Animal Ecology, 80, 393-402.

Tisseuil, C., Leprieur, F., Grenouillet, G., Vrac, M. \& Lek, S. (2012) Projected impacts of climate change on spatio-temporal patterns of freshwater fish beta diversity: a deconstructing approach. Global Ecology and Biogeography, 21, 1213-1222.

Ulrich, W. (2012) Turnover - a FORTRAN program for analysis of species associations. Available at: www.umk.pl/ $\sim$ ulrichw (accessed 17 June 2015).

Ulrich, W. \& Gotelli, N.J. (2012) A null model algorithm for presence-absence matrices based on proportional resampling. Ecological Modelling, 244, 20-27.

Ulrich, W. \& Gotelli, N.J. (2013) Pattern detection in null model analysis. Oikos, 122, 2-18.

Ulrich, W., Almeida-Neto, M. \& Gotelli, N.J. (2009) A consumer's guide to nestedness analysis. Oikos, 118, 3-17.

Wen, Z., Yang, Q., Quan, Q., Xia, L., Ge, D. \& Lv, X. (2016) Multiscale partitioning of small mammal $\beta$-diversity provides novel insights into the Quaternary faunal history of Qinghai-Tibetan Plateau and Hengduan Mountains. Journal of Biogeography, 43, 1412-1424.

Whittaker, R.J. \& Fernández-Palacios, J.M. (2007) Island biogeography: ecology, evolution, and conservation, 2nd edn. Oxford University Press, Oxford.

\section{SUPPORTING INFORMATION}

Additional Supporting Information may be found in the online version of this article:

Appendix S1 Regions of the Atlantic, Pacific and European realms.

Appendix S2 Range shapes in Atlantic NA and Europe.

Appendix S3 Spatial correlates of beta diversity and idiosyncrasy.

\section{BIOSKETCH}

David Griffiths is interested in fish biogeography and in the macroecology of body size distributions.

Editor: Jani Heino 